\title{
PENINGKATAN PRODUKSI PADI (Oryza sativa L.) MELALUI APLIKASI MACAM DAN KONSENTRASI BIOURINE
}

\section{IMPROVEMENT OF RICE (Oryza sativa L.) PRODUCTION THROUGH THE APPLICATION OF KIND AND CONCENTRATION OF BIOURINE}

\author{
Mokhammad Rizal Assari, Choirul anam dan Mariyatul Qibtiyah \\ Fakultas Pertanian Universitas Islam Darul 'Ulum Lamongan Jawa Timur \\ Korespondensi : rizalassari1997@gmail.com/mariyatulqibtiyah@unisda.ac.id
}

\begin{abstract}
ABSTRAK
Tanaman padi termasuk salah satu tanaman pangan yang tergolong rumput- rumputan (gramineae) dan merupakan sumber makanan pokok sebagian besar penduduk Indonesia. Pemakaian pupuk kimia yang berlebihan dapat mengakibatkan tertiggalnya residu sehingga kebutuhan unsur hara dalam tanah yang dibutuhkan tanaman semakin berkurang dengan penggunaan pupuk organik cair Biourine dapat menekan pemakaian pupuk kimia dimana Biourine membantu untuk menyuburkan tanah, menjaga stabilitas unsur hara dalam tanah, membantu memperbaiki produktivitas tanah dan meningkatkan kualitas produk. Penelitian ini dilaksanakan di Desa Sambungrejo, Kecamatan Modo, Kabupaten Lamongan. Ketinggian tempat 54.88 meter di atas permukaan laut $(\mathrm{mdpl})$. Waktu penelitian dilaksanakan pada bulan Februari sampai Mei 2020. Penelitian ini menggunakan metode rancangan acak kelompok (RAK) yang disusun secara faktorial dengan dua faktor perlakuan yaitu Konsentrasi Biourine dan Macam Biourine. Faktor Konsentrasi Biourine terdiri 3 perlakuan yaitu: 1:5 L, 1:10 L, 1:15. Faktor Macam Biourine terdiri dari 3 level yaitu: Tanpa Biourine / kontrol, Biourine Sapi, Biourine Kambing. Hasil penelitian yang telah dilakukan menunjukkan bahwa yang memberikan pengaruh yang lebih baik yaitu perlakuan konsentrasi 1:5 dan Biourine kambing dibandingkan dengan perlakuan yang lain.
\end{abstract}

Kata Kunci : Tanaman Padi, Pupuk Organik Cair Biourine, konsentrasi.

\begin{abstract}
Rice plants are one of the food plants classified as grasses (gramineae) and are the staple food source of most Indonesians. Excessive use of chemical fertilizers can cause residue to be left behind so that the need for nutrients in the soil that plants need is reduced by using liquid organic fertilizer Biourine can reduce the use of chemical fertilizers where Biourine helps to fertilize the soil, maintain nutrient stability in the soil, help revitalize soil productivity and improve product quality. This research was conducted in the village of Terkrejo, Modo District, Lamongan Regency. Altitude 54.88 meters above sea level (masl). The research was conducted from February to May 2020. This study used a randomized block design method (RBD) which was arranged factorial with two treatment factors, namely the concentration of Biourine and Kinds of Biourine. Biourine concentration factor consists of 3 treatments, namely: 1: 5 L, 1:10 L, 1:15 L. Types of Biourine consist of 3 levels, namely: No Biourine / control, Cow Biourine, Goat Biourine. better, namely the treatment concentration 1: 5 and goat biourine compared to other treatments.
\end{abstract}

Key words : rice plants, biourine liquid organic frtilizer, concentration. 


\section{PENDAHULUAN}

Tanaman padi adalah makanan pokok sebagian besar penduduk Indonesia. Total luas lahan untuk budidaya tanaman padi di Indonesia pada tahun 2010 mencapai 8 juta ha, sebagian besar budidaya padi dilakukan pada lahan sawah yaitu 4,9 juta ha $(61,25 \%)$ dan sebagian kecil 3,1 juta ha $(38,75 \%)$ di lahan keringnya. Produktivitas padi pada sawah adalah 4,75 ton ha ${ }^{-1}$ sedangkan produktivitas padi di lahan kering rata-rata 2,52 ton ha ${ }^{-1}$ (BPS Jatim 2012).

Penggunaan lahan di Kabupaten Lamongan, khususnya pada luas lahan sawah menurut jenis pengairannya meliputi irigasi dan non irigasi. Total luas lahan sawah dengan jenis pengairan irigasi pada tahun 2018 ialah 53.243 ha, sedangkan jenis pengairan non irigasi digunakan pada lahan sawah dengan seluas 34.590 ha. Berdasarkan data dinas pertanian lahan sawah di Kabupaten Lamongan bisa ditanami padi dan bukan padi. Lahan sawah yang ditanami padi bisa dipanen 1 kali, 2 kali dan 3 kali panen. Kabupaten Lamongan pada tahun 2018 bisa menghasilkan padi sebesar 1.053.796 t/ha. Sementara tanaman jagung yang bisa diproduksi oleh Kabupaten Lamongan pada tahun 2018 yaitu sebesar 372.162 ton/Ha. Dan produksi kedelai pada tahun 2018 sebesar 26.629,53 t/ha (BPS Lamongan, 2019).

Biourin diperoleh dari fermentasi anaerobik dari urine dengan nutrisi tambahan menggunakan mikroba pengikat nitrogen dan mikroba dekomposer lainnya. Biourin merupakan istilah yang populer dikalangan para pengembang pertanian organik. Biourin merupakan urin yang diambil dari ternak, terutama rumansia yang terlebih dahulu di fermentasi sebelum digunakan. Dengan demikian kandungan unsur nitrogen dalam biourin akan lebih tinggi dibandingkan dengan urine tanpa fermentasi. Urine sapi dapat dimanfaatkan sebagai bahan ramuan pestisida hewani (Anonymous, 2013). Biourine mengandung unsur hara organik yang diperlukan oleh tumbuhan padi selain unsur hara anorganik yang diberikan. Rahmatika (2009), menjelaskan bahwa unsur hara nitrogen sangat dibutuhkan tanaman utamanya pada fase vegetatif. Pertumbuhan tanaman akan mengalami peningkatan yang proporsional apabila unsur hara nitrogen tercukupi karena apabila kebutuhan nitrogen kurang pada fase pertumbuhan tanaman, maka akan terjadi pembatasan produksi dan pembentukan sel-sel baru yang akan menunjang pertumbuhan dan akan berdampak pada perkembangan tanaman.

Penelitian ini bertujuan untuk mengetahui pengaruh macam dan konsentrasi pemberian biourine pada pertumbuhan dan produksi tanaman padi (Oryza sativa L.).

\section{METODE PENELITIAN}

\section{Waktu dan Tempat}

Penelitian ini dilaksanakan di Desa Sambungrejo, kecamatan Modo, Kabupaten Lamongan. Dengan ketinggian tempat sekitar 54.88 (mdpl). Waktu penelitian dilaksanakan bulan Februari - Mei 2020.

\section{Bahan dan Alat}

Bahan yang digunakan dalam penelitian ini adalah benih tanaman padi varietas inpari 32 dan biourine sapi, biourine kambing, dan tanpa biourine, urea, phonska, petroorganik.

Alat yang digunakan antara lain: traktor, cangkul, gelas takaran, sabit, pisau, timbangan, meteran/penggaris, sprayer, timba/bak, plastik, gunting, papan nama, dan alat tulis penunjang lainnya.

\section{Metode Penelitian}

Penelitian dilakukan menggunakan metode Rancangan Acak Kelompok (RAK) faktorial, terdiri dari 2 faktor dan setiap faktor terdiri dari 3 level dengan 3 kali ulangan, yaitu: Faktor pertama konsentrasi 1 : $5 \mathrm{~L}, 1: 10 \mathrm{~L}, 1$ : $15 \mathrm{~L}$ factor kedua macam biourin control/tanpa biourine, biourine kambing dan biourine sapi. 


\section{PELAKSANAAN PENELITIAN}

\section{Pengolahan Lahan}

Sebelum tanah diolah, tanah digenangi air terlebih dahulu hingga rata dengan ketinggian air 5-7 cm diatas permukaan tanah untuk memudahkan pengolahan. Kemudian dilakukan pembajakan dan perataan tanah. Kedalaman lapisan olah tanah berkisar 10-30 $\mathrm{cm}$. Pengoahan tanah ini bertujuan untuk memberikan pertumbuhan padi yang optimal dan gulma yang ada dapat dibenamkan dengan baik setelah dilakukan pengolahan, tanah olahan dipetak-petak sesuai dengan perlakuan, ukuran masing-masing petak $2 \times 2$ meter dan diantara petak dan ulangan dibuatkan saluran air sekaligus sebagai pembatas antar petak dan ulangan.

\section{Persemaian}

Kebutuhan benih padi $30-40$ $\mathrm{kg} /$ hektar, sebelum penaburan benih dilahan persemaian benih dibenamkan dalam wadah yang berisi air selama 24 jam, setelah itu ditiriskan dan benih dibungkus karung selama 24 jam, setelah padi mulai ada titik tumbuh, kemudian ditaburkan diatas tanah persemaian yang telah disiapkan. Pada saat dipersemaian umur 10 hari dilakukan pemupukan agar bibit semakin kuat tak mudah patah jika dicabut nantinya.

\section{Pemindahan Binit}

Pemindahan bibit dilakukan 22 hari setelah dipersemaikan. Pemindahan dilakukan dengan mencabut bibit langsung dengan tangan dan diikat sesuai dengan keinginan, kemudian diletakkan disetiap petakan lahan.

\section{Penanaman}

Penanaman dilakukan langsung dengan tangan dengan kedalaman $3 \mathrm{~cm}$ dan kondisi air macak-macak, penanaman yang terlalu dalam memyebabkan pertumbuhan akar terlambat dan anakan berkurang, sehingga produksi berkurang. Penanaman dilakukan dengan posisi bibit yang tegak dengan jumlah tanaman satu lubang 3 batang rumpun pada lahan percobaan $2 \times 2$ meter dengan jarak $22 \mathrm{~cm}$ antar rumpun padi.

\section{Penyulaman}

Penyulaman dilakukan dengan tujuan agar pertumbuhan tanaman lebih seragam, penyulaman ini dilakukan apabila ada rumpun yang mati dan dilakukan pada tanaman berumur 7-14 hari setelah tanam, tanaman yang digunakan adalah bibit cadangan yang umunya sama/waktu persemaian sama.

\section{Pembuatan Biourine}

Biourine/Pupuk Organik Cair (POC) dibuat sendiri oleh peneliti dengan bahan sebagai berikut:

Komposisi untuk 50 liter biourine terdiri dari campuran 1 liter urin sapi, 5 kg kotoran padat sapi, 50 liter air, 1 kg jerami padi, 1 liter EM4 dan $220 \mathrm{ml}$ molase. Semua bahan dimasukan kedalam drum dan dibiarkan selama 2 minggu dalam keadaan tertutup. Setiap hari dibuka dan diaduk selama 15 menit. Setelah 2 minggu biourine siap digunakan dengan ditambah air sesuai dengan perlakuan kosentrasi untuk setiap 1 liter biourine.

\section{Pengairan}

Selain untuk pengolah lahan, air juga sangat penting untuk tanaman, yaitu untuk masa awal sampai akhir pertumbuhan (fase vegetatif - generatif). Sistem pemberian air pada padi adalah, pada saat tanaman sampai 3 hari setelah tanam tanah pada kondisi air macak-macak, 4 hari setelah tanam sampai 10 hari setelah tanam kondisi air setinggi $5 \mathrm{~cm} .11$ hari setelah tanam sampai menjelang berbunga air dibiarkan menyusut sendiri selama (5 hari), setelah kering pemberian air setinggi $5 \mathrm{~cm}$ dan kemudian dibiarkan lagi mengering sendiri, dan waktu berbunga sampai 10 hari sebelum panen pemberian air terus menerus setinggi $5 \mathrm{~cm}$. Kemudian pada umur 10 hari sebelum panen sampai panen petakan dikeringkan.

\section{Penyiangan}

Gulma bersaing dengan tanaman padi dalam hal cahaya matahari, unsur hara dan air. Persaingan ini akan menimbulkan pertumbuhan tanaman produksi menjadi kurang baik, sehingga hasil produksi gabah akan berkurang. Sehingga penyiangan dilakukan tidak terpaut waktu apabila ada gulma yang tumbuh makan dilakukan penyiangan yang dilakukan dengan 
cara mencabut langsung gulma dengan tangan.

\section{Pengendalian Hama dan Penyakit}

Pengendalian hama dan penyakit akan dilakukan ketika terdapat hama dan penyakit terjadi, cara pengendalian hama dan penyakit tersebut dilakukan dengan menggunakan insektisida kimia dan fungisida dengan cara mencampurkan dengan air sesuai takaran atau prosedur yang dianjurkan, kemudian disemprotkan ke tanaman dengan menggunakan handsprayer.

\section{Pengamatan}

Parameter pertumbuhan dengan mengamati lima tanaman contoh (sampel) untuk setiap petak. Pengamatan vegetatif dimulai pada umur 14 hst dengan interval 14 hari sekali sampai umur 42 hst. Sedangkan pengamatan fase generatif juga diukur dari mulai umur 56 hst interval 14 hst sampai umur 98 hst.

\section{Parameter Pertumbuhan}

Fase vegetatif, meliputi: Tinggi tanaman, Jumlah anakan dan Fase produksi, meliputi: Jumlah malai : diukur banyaknya malai tiap rumpun padi Bobot gabah 1000 bulir (g), Bobot gabah per petak (kg), Bobot gabah per hektar (ton).

\section{Pemanenan}

Pemanenan dilakukan pada umur 120 hari setelah tanam dan semua butir padi telah menguning. Kegiatan pemanenan dilakukan dengan memotong menggunakan sabit yang kemudian dilanjutkan dengan perontokan dengan manual, hal tersebut dilakukan karena untuk memudahkan proses pemisahan dari perlakuan perpetak.

\section{Pengeringan}

Pengeringan bertujuan untuk mengurangi kadar air yang ada didalam gabah agar aman untuk disimpan atau memudahkan penanganan selanjutnya. Pengeringan yang dilakukan adalah dengan cara alami, yaitu penjemuran dengan sinar matahari yang dihamparkan diatas penjemuran semen ataupun terpal.

\section{Analisis Data}

Data hasil pengamatan dari setiap parameter pada setiap pengamatan dianalisa dengan uji fisther (uji F) $5 \%$ dan 1\% jika terdapat perbedaan nyata, dilanjutkan dengan uji beda nyata terkecil ( BNT 5\%).

\section{HASIL DAN PEMBAHASAN}

\section{Tinggi Tanaman}

Berdasarkan hasil analisa sidik ragam menunjukkan bahwa terdapat interaksi antara perlakuan konsentrasi dan macam biourine terhadap pertumbuhan tinggi tanaman pada pengamatan umur 14, 28, 42 dan 56 hari setelah tanam. Selanjutnya dapat dilihat pada table 1.

Tabel 1. . Rata-rata tinggi tanaman (cm) pada umur 14, 28, 42 dan 56 hari setelah tanam.

\begin{tabular}{|c|c|c|c|c|}
\hline \multirow{2}{*}{ Perlakuan } & \multicolumn{4}{|c|}{ Rata-rata Tinggi Tanaman (cm) Pada Pengamatan Umur } \\
\hline & 14 hst & 28 hst & 42 hst & 56 hst \\
\hline Kontrol/Tanpa Biourine & $39,50 \mathrm{abc}$ & $56,10 \mathrm{f}$ & 80,09 abcde & 80,09 abcde \\
\hline 1:5 L + Biourine Sapi & $49,67 \mathrm{abc}$ & $68,00 \mathrm{bc}$ & 78,45 abcde & 78,45 abcde \\
\hline 1:5 L + Biourine kambing & $50,00 \mathrm{a}$ & 77,45 a & 82,45 a & $82,48 \mathrm{a}$ \\
\hline Kontrol/Tanpa Biourine & $49,67 a b$ & $74,67 a b$ & $82,23 \mathrm{abc}$ & $82,23 \mathrm{abc}$ \\
\hline 1:10 + Biourine Sapi & $38,30 \mathrm{abcd}$ & 58,88 def & 81,83 abcde & $81,87 \mathrm{abcd}$ \\
\hline 1:10 + Biourine Kambing & $35,27 \mathrm{e}$ & $55,00 \mathrm{f}$ & $77,03 \mathrm{f}$ & $77,03 \mathrm{e}$ \\
\hline Kontrol/Tanpa Biourine & $49,00 \mathrm{abcd}$ & 66,67 bcde & 77,33 def & 78,47 abcde \\
\hline 1:15 L + Biourine Sapi & 37,97 bcde & $67,20 \mathrm{bcd}$ & 81,97 abcd & 81,97 abcde \\
\hline 1:15 L + Biourine Kambing & 37,93 bcde & 61,63 cdef & $82,37 \mathrm{ab}$ & $82,38 \mathrm{ab}$ \\
\hline BNT 5\% & 11,86 & 8,83 & 4,77 & 4,52 \\
\hline
\end{tabular}

Keterangan : Angka-angka yang diikuti huruf yang sama dalam kolom yang sama tidak berbeda nyata dengan uji BNT 5\%.

Pada Tabel 1, menunjukkan bahwa perlakuan yang lebih baik didapatkan perlakuan R1Y2 pada pengamatan umur 14, 28 dan 42 hari setelah tanam yaitu dengan 
penggunaan konsentrasi 1:5 dan Biourine kambing yang ditunjukkan dengan notasi (a). Anova uji BNT 5\%.

Satu dari sumber limbah cair hewan ternak yang dapat dimanfaatkan menjadi biourine adalah urine sapi. Ignatius et al. (2014) mengemukakan bahwa hasil fermentasi biourine sapi mengandung hormon yang dapat mempengaruhi pertumbuhan dan perkembangan tanaman, yaitu hormon IAA yang dapat merangsang perakaran tanaman dan mempengaruhi proses perpanjangan sel, pembelahan sel, plastisitas dinding sel dan meningkatkan penyerapan air ke dalam sel.

Triwasana (2009) menyatakan bahwa biourine yang diberikan terhadap tanaman dapat meningkatkan pertumbuhan pada parameter jumlah daun yang lebih banyak.
Dengan pemberian pupuk yang mengandung unsur hara nitrogen yang cukup untuk kebutuhan tanaman maka pertumbuhan tanaman akan menjadi optimal khususnya pada fase vegetatif. Menurut Prihmantoro (2001), bahwa nitrogen dibutuhkan tanaman untuk merangsang pertumbuhan tanaman, terutama menambah tinggi tanaman, batang, dan daun.

\section{Jumlah Anakan Per Rumpun}

Hasil sidik ragam menunjukan bahwa terdapat interaksi antara perlakuan macam dan konsentrasi biourine pada pengamatan jumlah anakan per rumpun umur 14, 28, 42 dan 56 hari setelah tanam. Hasil uji BNT 5\% seperti Tabel dibawah ini.

Tabel 2. Rerata Banyak Anakan per rumpun (buah) pada umur 14, 28, 42 dan 56 hari setelah tanam.

\begin{tabular}{|c|c|c|c|c|}
\hline \multirow{2}{*}{ Perlakuan } & \multicolumn{4}{|c|}{ Rata-rata Banyak Anakan (buah) Pada Pengamatan Umur } \\
\hline & 14 hst & 28 hst & 42 hst & 56 hst \\
\hline Kontrol/Tanpa Biourine & $19,13 \mathrm{de}$ & $28,00 \mathrm{e}$ & $30,00 \mathrm{de}$ & $30,00 \mathrm{e}$ \\
\hline 1:5 L + Biourine Sapi & $49,67 a b$ & $49,67 a b c$ & $49,67 \mathrm{abc}$ & $49,67 a b c$ \\
\hline 1:5 L + Biourine kambing & $50,00 \mathrm{a}$ & $50,33 \mathrm{a}$ & 50,67 a & $51,00 \mathrm{a}$ \\
\hline Kontrol/Tanpa Biourine & $49,33 \mathrm{abc}$ & $50,10 a b$ & $50,33 a b$ & $50,33 a b$ \\
\hline 1:10 L + Biourine Sapi & 7,60 e & $18,80 \mathrm{e}$ & $23,27 \mathrm{e}$ & 29,07 e \\
\hline 1:10 L + Biourine Kambing & 6,67 e & $18,07 \mathrm{e}$ & 21,27 e & $26,33 \mathrm{e}$ \\
\hline Kontrol/Tanpa Biourine & $39,80 \mathrm{abcd}$ & $44,67 \mathrm{abcd}$ & $45,40 \mathrm{abcd}$ & $45,40 \mathrm{abcd}$ \\
\hline 1:15 L + Biourine Sapi & 7,33 e & 20,27 e & $26,27 \mathrm{e}$ & 26,27 e \\
\hline 1:15 L + Biourine Kambing & 8,00 e & $22,20 \mathrm{e}$ & $25,93 \mathrm{e}$ & $25,93 \mathrm{e}$ \\
\hline BNT 5\% & 22,36 & 16,54 & 15,71 & 15,27 \\
\hline
\end{tabular}

Keterangan : Angka-angka yang diikuti huruf yang sama dalam kolom yang sama tidak berbeda nyata dengan uji BNT 5\%.

Pada Tabel 2, dapat dilihat bahwa pada parameter pengamatan jumlah anakan menunjukkan kombinasi perlakuan RIY2 yaitu menggunakan konsentrasi 1:5 dan biourine kambing menghasilkan hasil yang lebih baik ditunjukkan dengan notasi (a).

Pengaruh pemberian pupuk cair organik dapat memberikan pengaruh pada pengamatan jumlah anakan per rumpun pada umur 14, 28, 42 dan 56 hari setelah tanam. $\mathrm{Hal}$ ini terjadi karena pengaruh lingkungan yang sangat mendukung, yauitu unsur hara yang terkandung dalam tanah yang baik, ketersediaan air yang cukup, suhu, penyinaran matahari yang optimal tanpa terganggu oleh pepohonan dan penggunaan pupuk organik cair. Husnah (2010) menyatakan jika keadaan lingkungan yang menguntungkan atau sesuai dengan pertumbuhan dan perkembangan ditambah dengan tanaman memiliki sifat genetik yang baik maka jumlah anakan dapat tumbuh dengan maksimal. Komponen yang berpengaruh langsung terhadap tinggi rendahnya hasil gabah ditentukan oleh jumlah anakan produktif per rumpun atau per satuan luas termasuk jumlah malai (Simanulang, 2001).

Semakin banyak jumlah malai yang terbentuk maka semakin banyak anakan yang dihasilkan 


\section{Jumlah Malai}

Hasil sidik ragam menunjukan bahwa terdapat interaksi antara perlakuan macam dan konsentrasi biourine pada pengamatan jumlah malai pada umur 60 dan 74 hari setelah tanam.

Tabel 3. Rerata Jumlah Malai (buah) pada umur 60 dan 74 hari setelah tanam

\begin{tabular}{|c|c|c|}
\hline \multirow{2}{*}{ Perlakuan } & \multicolumn{2}{|c|}{ Rata-rata Jumlah Malai (buah) Pada Umur } \\
\hline & 60 hst & 74 hst \\
\hline Kontrol/Tanpa Biourine & $25,00 \mathrm{de}$ & $25,07 \mathrm{de}$ \\
\hline 1:5 L + Biourine Sapi & $49,67 a b$ & $49,67 a b c$ \\
\hline 1:5 L + Biourine kambing & $50,00 a$ & $50,00 \mathrm{a}$ \\
\hline Kontrol/Tanpa Biourine & $49,33 \mathrm{abc}$ & $49,77 a b$ \\
\hline 1:10 L + Biourine Sapi & $15,20 \mathrm{e}$ & $15,27 \mathrm{e}$ \\
\hline 1:10 L + Biourine Kambing & $14,00 \mathrm{e}$ & $14,47 \mathrm{e}$ \\
\hline Kontrol/Tanpa Biourine & $41,73 \mathrm{abcd}$ & $41,87 \mathrm{abcd}$ \\
\hline 1:15 L + Biourine Sapi & $14,73 \mathrm{e}$ & $15,13 \mathrm{e}$ \\
\hline 1:15 L + Biourine Kambing & $17,40 \mathrm{e}$ & $17,80 \mathrm{e}$ \\
\hline BNT 5\% & 19,38 & 19,28 \\
\hline
\end{tabular}

Keterangan : Angka-angka yang diikuti huruf yang sama dalam kolom yang sama tidak berbeda nyata dengan uji BNT 5\%.

Pada Tabel 3, menunjukan bahwa jumlah malai yang terbaik dalam pengamatan yang sudah dilakukan oleh peneliti terdapat pada perlakuan R1Y2 yaitu dengan menggunakan 1:5 liter dan biourine kambing pada umur 60 dan 74 hari setelah tanam. Berdasarkan dari aroma pupuk iourine memang lebih bau dibandingkan pupuk kandang padat, namun bourine memiliki berbagai keunggulan. Pupuk cair mengandung nutrisi yang dibutuhkan untuk pertumbuhan dan perkembangan tanaman. Nutrisi itu terdiri dari nitrogen $(\mathrm{N})$, fosfor $(\mathrm{P})$,

Tabel 4. Rerata Bobot Gabah (gram) 1000 Bulir dan kalium (K). Nitrogen digunakan untuk pertumbuhan tunas, batang dan daun. Sedangkan untuk merangsang pertumbuhan akar, buah, dan biji menggunakan fosfor (P). Ketahanan tanaman terhadap organisme pengganggu tanaman dapat ditingkatkan melalui penggunaan kalium (Setiawan, 2007).

\section{Bobot Gabah 1000 Bulir}

Hasil sidik ragam menunjukan bahwa terdapat interaksi antara perlakuan macam dan konsentrasi biourine pada parameter pengamatan bobot seribu bulir. Hasil uji BNT5\% seperti tabel dibawah ini.
Perlakuan

Rata-rata Jumlah Bobot Seribu Bulir (gram)

\begin{tabular}{lc}
\hline Kontrol/Tanpa Biourine & $50,00 \mathrm{~d}$ \\
$1: 5 \mathrm{~L}+$ Biourine Sapi & $56,00 \mathrm{~cd}$ \\
$1: 5 \mathrm{~L}+$ Biourine kambing & $65,17 \mathrm{a}$ \\
Kontrol/Tanpa Biourine & $53,33 \mathrm{~cd}$ \\
1:10 L + Biourine Sapi & $60,00 \mathrm{abc}$ \\
$1: 10 \mathrm{~L}+$ Biourine Kambing & $51,33 \mathrm{~cd}$ \\
Kontrol/Tanpa Biourine & $65,00 \mathrm{ab}$ \\
1:15 L + Biourine Sapi & $55,00 \mathrm{~cd}$ \\
1:15 L + Biourine Kambing & $50,00 \mathrm{~d}$ \\
\hline BNT 5\% & $\mathbf{8 , 7 8}$ \\
\hline
\end{tabular}

Keterangan : Angka-angka yang diikuti huruf yang sama dalam kolom yang sama tidak berbeda nyata dengan uji BNT $5 \%$. 
Pada Tabel 4, perlakuan R1Y2 menggunakan konsentrasi 1:5 liter dan biourine kambing menunjukan bobot gabah yang lebih baik. Dengan menggunakan pemakaian biourin yang tepat akan menghasilkan produksi padi lebih baik. Sedangkan menurut Apriyanto, (2012) yang menyatakan meningkatnya proses fotosintesis akan meningkatkan hasil tanaman. Bahan kering dalam biji diperoleh dari fotosintesis yang selanjutnya dapat digunakan untuk

Tabel 5. Rerata bobot gabah (kg) per petak. pengisian biji sesuai dengan pendapat rahmi (2011) yang menyatakan bahwa rata-rata berat biji sangat ditentukan oleh bentuk dan ukuran biji pada suatu varietas.

\section{Bobot Gabah Per Petak}

Hasil sidik ragam menunjukan bahwa terdapat interaksi antara perlakuan macam dan konsentrasi biourine pada parameter pengamatan bobot gabah per petak. Hasil uji BNT5\% seperti tabel dibawah ini.

\section{Perlakuan}

Kontrol/Tanpa Biourine

1:5 $L+$ Biourine Sapi

1:5 L + Biourine kambing

Kontrol/Tanpa Biourine

1:10 L + Biourine Sapi

1:10 L + Biourine Kambing

Kontrol/Tanpa Biourine

1:15 L + Biourine Sapi

1:15 $L+$ Biourine Kambing

\section{Rata-rata bobot gabah per petak (kg)}

2,74 abcd

$2,87 \mathrm{ab}$

2,93 a

$2,71 \mathrm{abcd}$

2,57 abcd

$2,60 \mathrm{abcd}$

$2,30 \mathrm{abcd}$

$2,47 \mathrm{abcd}$

$2,80 \mathrm{abcd}$

\section{BNT 5\%}

0,92

Keterangan : Angka-angka yang diikuti huruf yang sama dalam kolom yang sama tidak berbeda nyata dengan uji BNT 5\%.

Pada Tabel 5, menunjukan adanya interaksi pada perlakuan R1Y2 yaitu konsentrasi 1:5 dan biourine kambing yang ditandai dengan notasi (a). Sifat-sifat dari suatu varietas tidak selalu tetap, tetapi telah mengalami perubahan, sehingga suatu varietas yang unggul pada suatu waktu dan tempat yang berbeda, syarat pembudidayaan yang dikehendaki varietas unggul baru berbeda dengan varietas yang lama. Untuk penanaman pada daerah baru masih terdapat sifat-sifat yang tidak maksimal (Sri Setyati, 1999).

Menurut Astanto Kasno, et al., (1995), Varietas adalah sekelompok tanaman yang mempunyai keunikan yang seragam dan stabil serta mengandung perbedaan yang jelas dari varietas yang lain, sehingga masing-masing Varietas mempunyai sifat-sifat yang khusus antara lain keunggulan agronomi. Tanaman padi dikatakan unggul apabila mempunyai sifat yang lebih baik dari varietas sebelumnya, predikat varietas unggul yang diberikan pada tanaman berlaku sebelum diketemukan varietas baru yang dapat menandingi varietas yang terdahulu atau yang sudah bersertifikasi dari sifat-sifatnya dalam pertumbuhan maupun dalam perkembangan tanamannya.

\section{Bobot Gabah Per Hektar}

Pada Tabel 6, menunjukan adanya interaksi pada perlakuan konsentrasi 1:5 dan biourine kambing yang disajikan dengan notasi (a). 
Tabel 6. Rata-Rata bobot gabah per hektar

Perlakuan

Kontrol/Tanpa Biourine

1:5 L + Biourine Sapi

1:5 L + Biourine kambing

Kontrol/Tanpa Biourine

1:10 L + Biourine Sapi

1:10 L + Biourine Kambing

Kontrol/Tanpa Biourine

1:15 L + Biourine Sapi

1:15 $L+$ Biourine Kambing

BNT 5\%

Beberapa penelitian menunjukan bahwa dengan penggunaan biourine pada tanaman, mampu meningkatkan produksi tanaman termasuk tanaman padi melalui aktivasi mikroorganisme yang terkandung di dalamnya maupun di lingkungan (Suriardika, dkk. 2006). Adanya perbedaan yang nyata dari pengaruh konsentrasi POC tersebut terhadap tinggi tanaman pada umur 21 hari setelah tanam dan pada saat panen serta jumlah daun pada umur 21 hari setelah tanam disebabkan dengan bertambahnya umur tanaman, sehingga kebutuhan unsur hara tanaman juga bertambah banyak dan hal tersebut tidak semuanya dapat dipenuhi oleh media tanam tumbuh tanaman. Sesuai dengan pendapat Mulyani Sutejo (2002).

\section{KESIMPULAN}

Hasil parameter pengamatan yang telah dilakukan menunjukkan adanya interaksi antara konsentrasi dan macam biourin pada parameter tinggi tanaman umur 14 hst sampai 42 hst, serta jumlah anakan per rumpun pada umur 14 hst sampai 42 hst. Hasil parameter pengamatan juga menunjukkan adanya interaksi pada perlakuan konsentrasi dan macam biourin pada parameter produksi yaitu jumlah malai, bobot gabah 1000 bulir, bobot gabah per petak dan bobot gabah per hektar. Perlakuan biourine kambing dan konsentrasi 1:5 menghasilkan nilai yang lebih baik dibandingkan dengan perlakuan yang lainnya.
Rata-rata bobot gabah per hektar (ton/Ha)
$5,79 a b c$
$5,82 \mathrm{ab}$
5,93 a
5,68 abcd
5,37 abcd
5,45 abcd
4,56 abcd
5,12 abcd
$5,31 \mathrm{abcd}$

4,26

\section{SARAN}

Penelitian ini dapat dilajutkan dengan perlakuan macam dan konsentrasi biourine di lahan sawah dengan lokasi uang berbeda, sehingga dapat mengetahui peningkatan hasil yang terbaik lagi antara macam dan konsentrasi biourine. Penelitian ini dapat dilanjutkan dengan menambahkan perlakuan macam biourine seperti biourine kelinci.

\section{DAFTAR PUSTAKA}

BPS. Jatim 2016. Provinsi Jawa Timur dalam angka.

BPS. Kabupaten Lamongan. 2019. Lamongan dalam angka.

Anonymous.2013.http://m.epetani.deptan.go .id. 2013. Urine Sapi Di Buang Sayang.http://m.epetani.deptan.g o.id/berita/urine-sapidibuangsayang-7753.Diakses tanggal 16 september 2015.

Rahmatika. 2009. Pengaruh Presentase N (Azola dan Urea) Terhadap Pertumbuhan dan Hasil Tanaman Padi (Oryza sativa L). Tesis. Universitas Brawijaya Malang.

Ignatius, H., Irianto dan A. Riduan. 2014. Respon Tanaman Terung (Solanum melongena L.) terhadap Pemberian Pupuk Organik Cair Urine Sapi. Jurnal Penelitian Universitas Jambi Seri Sains. 16(1): 31-38.

Prihmantoro. 2001. Pengaruh nitrogen pada tanaman. 
Triwasana, L. R. D. 2009. Pengaruh Dosis Pupuk Urea dan Urine Sapi Pada Tanaman Kacang Hijau (Vigna radiata)

Husna, Y. 2010. Pengaruh Penggunaan Jarak Tanam Terhadap Pertumbuhan danProduksi Padi Sawah (Oryza sativa L.) Varietas IR 42 dengan Metode SRI (System of Rice Intensification). Jurnal. Jurusan Agroteknologi. Fakultas Pertanian. Universitas Riau. Vol(9):2-7.

Simanulang, Z. A. 2001. Status Penelitian Pemuliaan Padi Untuk Memenuhi Kebutuhan Pangan Masa Depan. Balai Penelitian Tanaman Padi, Sukamandi.

Setiawan, A.I. 2007. Memanfaatkan Kotoran Ternak. Penebar Swadaya Jakarta.

Astanto Kasno, 1995. Perkembangan Varietas Kacang Tanah. Monograt Balittan Malang No. 121993. Malang, 31 hal.Augusts, P., L.A. Taulu, dan D. Polakitan, 2011. Kajian beberapa varietas unggul baru padi sawah di Kabupaten Minahasa. Prosiding Seminar Nasional Serealia, Maros Sulawesi Selatan. Hal. 130-133.

Sri Setyati Harjad, 1999. Pengantar Agronomi. Gramedia. Jakarta. 187 hal.

Suriardika, Didi Ardi., Simanungkalit, R.D.M. (2006). Pupuk Organik dan Pupuk Hayati. Jawa Barat: Balai Besar Penelitian dan Pengembangan Sumberdaya Lahan Pertanian. Hal 2. ISBN 978-9799474-57-5.

Mulyani Sutejo. 2002. Pupuk dan Cara Pemupukan. Bina Aksara, Jakarta.

Rahimi, Z. Zuhry, E. Nurbaiti. 2011. Pengaruh Jarak Tanam Terhadap Pertumbuhan dan Produksi Padi Sawah (Oryza sativa L.) Varietas Batang Piaman dengan Metode System of Rice Intensification (SRI) di Padang Marpoyan Pekanbaru. Jurnal. Fakultas Pertanian. Universitas Riau. Hal 7. 